\title{
The Contribution of Health Literacy to Disparities in Self-Rated Health Status and Preventive Health Behaviors in Older Adults
}

Ian M. Bennett, $M D, P b D^{1-3}$

Jing Chen, $P h D^{4}$

Jaleb S. Soroui, MLS ${ }^{4}$

Sheida White, $P b D^{5}$

'Department of Family Medicine and Community Health, University of Pennsylvania School of Medicine, Philadelphia, Pennsylvania

${ }^{2}$ Leonard Davis Institute of Health Economics, University of Pennsylvania School of Medicine, Philadelphia, Pennsylvania

${ }^{3}$ Center for Public Health Initiatives University of Pennsylvania, Philadelphia, Pennsylvania

${ }^{4}$ American Institutes for Research, Washington, DC

${ }^{5}$ National Center for Education Statistics, US Department of Education, Washington, DC

Conflicts of interest: none reported.

\section{CORRESPONDING AUTHOR}

Ian Bennett, MD, PhD

2nd Floor, Gates Pavilion

3400 Spruce St

Philadelphia, PA 19104

ian.bennett@uphs.upenn.edu

\begin{abstract}
PURPOSE Health literacy is associated with a range of poor health-related outcomes. Evidence that health literacy contributes to disparities in health is minimal and based on brief screening instruments that have limited ability to assess health literacy. The purpose of this study was to assess whether health literacy contributes, through mediation, to racial/ethnic and education-related disparities in self-rated health status and preventive health behaviors among older adults.
\end{abstract}

METHODS We undertook a cross-sectional study of a nationally representative sample of 2,668 US adults aged 65 years and older from the 2003 National Assessment of Adult Literacy. Multiple regression analysis was used to assess for evidence of mediation.

RESULTS Of older adults in the United States, 29\% reported fair or poor health status, and $27 \%$ to $39 \%$ reported not utilizing 3 recommended preventive health care services in the year preceding the assessment (influenza vaccination $27 \%$, mammography 34\%, dental checkup 39\%). Health literacy and the 4 health outcomes (self-rated health status and utilization of the 3 preventive health care services) varied by race/ethnicity and educational attainment. Regression analyses indicated that, after controlling for potential confounders, health literacy significantly mediated both racial/ethnic and education-related disparities in self-rated health status and receipt of influenza vaccination, but only education-related disparities in receipt of mammography and dental care.

CONCLUSIONS Health literacy contributes to disparities associated with race/ethnicity and educational attainment in self-rated health and some preventive health behaviors among older adults. Interventions addressing low health literacy may reduce these disparities.

Ann Fam Med 2009;7:204-211. DOI: 10.1370/afm.940.

\section{INTRODUCTION}

A dults aged 65 years and older represent the largest single group in the United States who have limited general literacy and health literacy skills., ${ }^{1,2}$ Simultaneously, the elderly have the highest proportion of chronic illness of any age-group. If they are used, health care services for preventable illnesses are effective in reducing morbidity and mortality among older adults. ${ }^{3}$ The elderly, however, comprise a vulnerable population that is negatively affected by limited health literacy, which creates barriers to the use of these preventive services. ${ }^{4,5}$

Significant differences in health status and preventive care utilization among older adults are well documented. ${ }^{5-9}$ Particularly troubling are disparities in the use and delivery of immunizations and cancer screening related to race/ethnicity and educational attainment. ${ }^{6-12}$ It is commonly thought that health literacy (the ability to use health information from 
any source to make appropriate health decisions) is an important contributor to these disparities. ${ }^{13,14}$ Despite calls for research in this area, there has been little effort to assess formally the contribution of health literacy to disparities in health., 3,15 The only study that has addressed this question directly was limited to members of a single regional insurance carrier. ${ }^{16}$ In addition, limitations in the screening instruments widely used to estimate health literacy undermine the importance of previous findings. These brief instruments are convenient for large studies that primarily aim to assess health outcomes. ${ }^{17-20}$ Rather than measuring health literacy skills directly, these instruments estimate reading skills in the health context. ${ }^{13,20,21}$ That is, they have limited ability to assess the functional capacity of an adult to use printed and written healthrelated materials to perform a range of health-related tasks, a critical component of health literacy. ${ }^{15,21,22}$ Although these instruments have been crucial in building an evidence base for the link between literacy and health outcomes, additional research using more-rigorous measures of health literacy are needed to confirm previous studies and solidify this developing field. ${ }^{22-25}$

The current study makes use of data from the health literacy component of the 2003 National Assessment of Adult Literacy (NAAL) to test the hypothesis that health-related print literacy contributes to racial/ethnic and education-related disparities in self-rated health status and the receipt of 3 preventive health services in a nationally representative sample of older Americans: influenza vaccination, mammography, and dental care.

\section{METHODS}

Details regarding sample selection, response rate, and interview procedure have been reported elsewhere. ${ }^{2}$ The 2,668 nonincarcerated adults aged 65 years and older who were included in this study were among the more than 18,000 adults comprising the household sample of the 2003 NAAL. The NAAL household sample, representative of all adults aged 16 and older living in US households, was selected using a 4-stage stratified area design. Area segments classified as minority (ie, more than $25 \%$ black or Hispanic) were oversampled. The overall weighted response rate for the household sample was $62.1 \%$.

A sample of more than 1,000 individuals from the nation's federal and state prisons was not included in this study because these adults were not asked about preventive health practices. Additionally, we excluded adults who could not be interviewed because of language barriers or mental disability (about $3 \%$ of the NAAL household sample).

\section{Procedure}

From March 2003 through January 2004, approximately 400 trained interviewers (including those bilingual in English and Spanish) visited households to select and privately interview adults. The background questionnaires were administered orally in either English or Spanish, whichever language the participant chose. The oral administration and the Spanish-language option enabled more adults at the low end of the literacy continuum to understand and answer the questions about their backgrounds. Upon completion of the background questionnaires, participants were given booklets containing literacy assessment questions, all of which were in English. Participants generally completed the background interviews and assessments in about 90 minutes.

\section{Measures}

The NAAL instruments relevant to this study are (1) the background questionnaire, which included items relating to health status and behaviors, and (2) the health literacy component of the main literacy assessment. NAAL participants rated their current health on a 5-point scale (excellent, very good, good, fair, poor). Self-rated health status predicts disability and overall health status measured objectively. ${ }^{26}$ In addition, participants were asked whether they had been vaccinated against influenza, had visited a dentist, and (for female participants) had received a mammogram in the year preceding the assessment. The answers to the preventive health behaviors questions were categorized as yes or no based on the participants' responses. The background questionnaire included a range of self-reported demographic characteristics.

Development of the NAAL health literacy scale and the performance levels are detailed elsewhere. ${ }^{2,27}$ Briefly, the main NAAL assessment included 152 items or tasks, 28 of which were health-related and constituted the health literacy assessment. Two of the 28 health-related tasks were repeated from the 1992 National Adult Literacy Survey (NALS) administered by the National Center for Education Statistics (NCES).

Every task was classified as 1 of the basic literacy types measured by NAAL_ - prose literacy (eg, reading a consent form), document literacy (eg, filling out a health insurance form), or quantitative literacy (eg, calculating a health care bill). Participant responses to the 28 health-related tasks (12 prose, 12 document, and 4 quantitative items) were combined to yield a single health literacy score. To facilitate meaningful reporting of adult performance, NAAL grouped health literacy scores into 4 performance levels: below basic, basic, intermediate, and proficient.

The materials used for the health-related tasks were everyday texts and documents either in their original 
form or reproduced in assessment booklets. The tasks were organized around 3 domains of health and health care information and services: clinical (eg, understanding dosing instructions for medication), preventive (eg, understanding guidelines for age-appropriate preventive health services), and navigation of the health care system (eg, determining eligibility for public assistance programs). Designed to measure functional literacy, none of the tasks required knowledge of specialized health terminology.

Potentially confounding demographic variables were identified a priori through a review of the literature on literacy and health in older adults. Demographic variables were age, sex, income, nativity (US born), and marital status. ${ }^{7-12,13}$

\section{Statistical Analysis}

Statistical analyses, which included the health literacy measure, were carried out using AM software, ${ }^{28}$ the only software that can be used for secondary analyses of the NAAL literacy data with its complex sampling design. This software estimates regression models involving a literacy variable through the marginal maximum likelihood (MML) method. ${ }^{29}$ The MML method was used because the NAAL used a balanced incomplete block spiraling design (that is, administering each participant about 40 of the 152 assessment tasks) to reduce the burden on individual participants while ensuring full content coverage from an aggregate perspective. Because not everyone received the full set of assessment tasks, large measurement errors make it inappropriate to estimate the literacy of individuals. The MML direct estimation procedure represents each respondent's literacy proficiency as a probability distribution over all possible scores and uses these probability distributions in the estimation process. ${ }^{30}$ Health literacy was measured on the item response theory (IRT) theta scale, typically ranging from -3 to 3 . The theta scale can be transformed to a 0 to 500 metric, as is done in all NAAL publications of NCES, as follows: $\theta^{*}=51.99 \times \theta+247.37$, where $\theta$ is the scale from IRT item calibration and $\theta^{*}$ is the 0 to 500 scale.

Assessment of the potential mediation effect of health literacy was assessed using the criteria of Barron and Kenney. ${ }^{31}$ The hypothesized mediation model guiding this analysis is displayed in Figure 1. To satisfy the criteria for mediation, (1) the association of the primary independent variable (race/ethnicity and education) with the potential mediator (health literacy) must be significant (ie, $a \neq 0$ in the figure); (2) the association of the primary independent variable (race/ethnicity and education) with the dependent variable (health status or each of the 3 preventive health behaviors) must be significant (ie, $c \neq 0$ ); and (3) the mediator (health literacy) must be significantly associated with the dependent variable controlling for the primary independent variable $(i e, b \neq 0)$. If these requirements are satisfied in the predicted direction, and the association between the primary independent variable and the dependent variable is significantly reduced with the inclusion of the potential mediator in the model (ie, c' is statistically smaller than c), mediation is said to have occurred. The significance of the mediation effect of health literacy was tested using the Sobel test. ${ }^{32,33}$

Potential confounding demographic variables were assessed for association with the independent variables $(P<.05)$. Variables were included in multiple regression models only if they had an association with race/ethnicity or educational attainment. Conceptually, mediation and confounding are distinct. ${ }^{34}$ The mediation model assumes a pathway, in which an independent variable affects a mediator, which in turn affects a dependent
Figure 1. Conceptual model: the mediation effect of health literacy on racial/ethnic and educational disparities in health and preventive health behaviors in older adults.

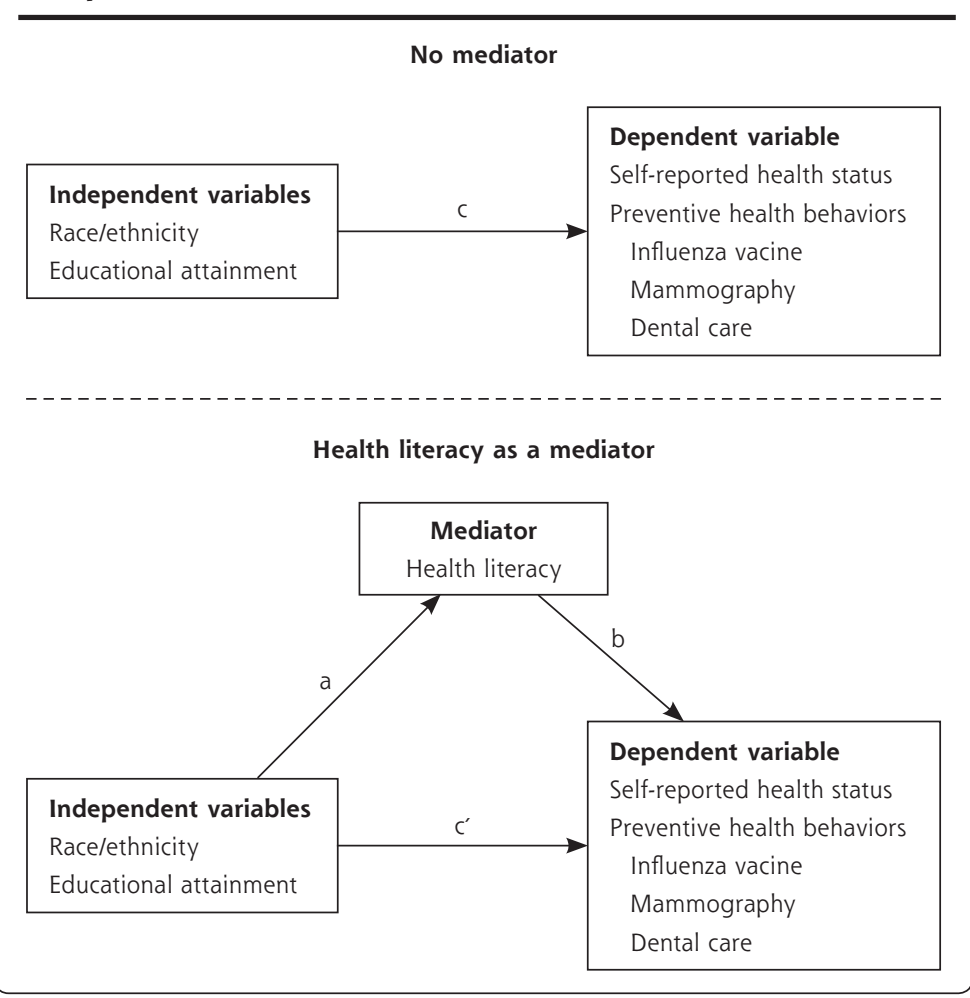




\begin{tabular}{|c|c|c|}
\hline Variables & Frequency ${ }^{a}$ & $\begin{array}{l}\text { Weighted } \\
\text { Percentage } \\
\text { (SE) }\end{array}$ \\
\hline \multicolumn{3}{|l|}{ Independent Variables } \\
\hline \multicolumn{3}{|l|}{ Health literacy level } \\
\hline Below basic & 950 & $29.0(1.4)$ \\
\hline Basic & 736 & $29.5(0.8)$ \\
\hline Intermediate & 894 & $38.2(1.3)$ \\
\hline Proficient & 85 & $3.3(0.5)$ \\
\hline \multicolumn{3}{|l|}{ Race/ethnicity } \\
\hline White (non-Hispanic) & 2,037 & $85.3(1.3)$ \\
\hline Black (non-Hispanic) & 352 & $7.3(0.9)$ \\
\hline Latino/Hispanic & 209 & $5.1(1.0)$ \\
\hline Other & 70 & $2.3(0.7)$ \\
\hline \multicolumn{3}{|l|}{ Education } \\
\hline >High school & 987 & $37.3(1.5)$ \\
\hline High schoolb & 788 & $38.5(1.4)$ \\
\hline$<$ High school & 888 & $24.3(1.4)$ \\
\hline \multicolumn{3}{|l|}{ Age } \\
\hline $65-74$ y & 1,439 & $55.2(1.2)$ \\
\hline $75-84$ y & 988 & $36.5(1.1)$ \\
\hline $85+y$ & 241 & $8.3(0.8)$ \\
\hline \multicolumn{3}{|l|}{ Sex } \\
\hline Male & 1,036 & $44.9(1.1)$ \\
\hline Female & 1,632 & $55.1(1.1)$ \\
\hline \multicolumn{3}{|l|}{ Income } \\
\hline Above $175 \%$ threshold & 1,141 & $58.6(1.6)$ \\
\hline $100 \%-175 \%$ above threshold & 594 & $23.0(1.4)$ \\
\hline Below poverty threshold & 584 & $18.4(1.3)$ \\
\hline \multicolumn{3}{|l|}{ Nativity } \\
\hline US born & 2,421 & $92.2(0.9)$ \\
\hline Foreign born & 246 & $7.8(0.9)$ \\
\hline \multicolumn{3}{|l|}{ Dependent Variables } \\
\hline \multicolumn{3}{|l|}{ Self-rated health status } \\
\hline Fair/poor & 887 & $29.3(1.1)$ \\
\hline Excellent/very good/good & 1,777 & $70.7(1.1)$ \\
\hline \multicolumn{3}{|l|}{ Influenza vaccinationc } \\
\hline No & 793 & $27.7(1.4)$ \\
\hline Yes & 1,866 & $72.3(1.4)$ \\
\hline \multicolumn{3}{|l|}{ Mammogramc } \\
\hline No & 576 & $34.0(1.7)$ \\
\hline Yes & 1,041 & $66.0(1.7)$ \\
\hline \multicolumn{3}{|l|}{ Dental checkup } \\
\hline No & 1,154 & $39.3(1.6)$ \\
\hline Yes & 1,506 & $60.7(1.6)$ \\
\hline
\end{tabular}

Note: Standard errors are in parentheses. Detail may not sum to totals because of rounding. Older adults are defined as people aged 65 years and older living in households.

Source: Data used are from the 2003 National Assessment of Adult Literacy, conducted by the National Center for Education Statistics, Institute of Education Sciences, us Department of Education.

a Unweighted absolute frequency in sample.

${ }^{b}$ High school diploma or equivalency degree.

' Self-reported utilization of care in the year preceding the assessment. variable. In contrast, a confounding variable does not lie in a causal pathway between the independent and the dependent variable, even though it is statistically associated with both. For this reason, it is crucial to identify potential confounding variables and account for their effects in statistical models (by controlling for them) when assessing potential mediators, so that the independent effect of mediation can be elucidated.

All analyses were conducted based on weighted data adjusted for unequal probability of selection and nonresponse. A $P$ value of .05 was used to determine statistical significance.

\section{RESULTS}

As shown in Table 1 most adults aged 65 and older were non-Hispanic white $(85.3 \%)$, more than one-half $(55.2 \%)$ were between the ages of 65 and 74 years, and $55.1 \%$ were female. Their socioeconomic status was diverse, with $18.4 \%$ in poverty and $24.3 \%$ lacking a high school diploma. In addition, $92.2 \%$ were born in the United States. Approximately one-third (29.3\%) of these older adults reported poor or fair health status in 2003; simultaneously, $27.7 \%$ to $39.3 \% \%$ reported not utilizing the targeted preventive health services-influenza vaccination, mammography, and dental care-in the year preceding the assessment. Significant racial/ ethnic and education-associated disparities were found in bivariate analysis of unadjusted rates of self-reported health and most of the preventive health behaviors examined (Table 2). Black and Latino respondents were about 1.5 times more likely to report fair or poor health than white respondents. Likewise, older adults with less than high school educational attainment were 2.4 times as likely to report fair or poor health than those with greater than high school attainment ( $48 \%$ vs $20 \%$ ). For reported preventive health behaviors, black older adults were less likely than whites to have had an influenza vaccination or dental check up, but not mammography. Latinos were not significantly different from the other 2 groups. Older adults with less than high school educational attainment were less likely to have received all of these services than those with greater than high school attainment.

To determine whether health literacy satisfied the first criterion of a potential mediator, we tested the association of the 2 primary independent variables, race/ethnicity and educational attainment, with the health literacy score. Bivariate analyses (not displayed) without controlling for confounding variables showed that white older adults had an average health literacy score of 220 (within the basic level), which was significantly higher than the averages of the black older adults (172, within the below basic level) and the 


\begin{tabular}{|c|c|c|c|c|}
\hline Variable & $\begin{array}{l}\text { Poor or Fair } \\
\text { Self-rated } \\
\text { Health Status } \\
\%(95 \% \mathrm{Cl})\end{array}$ & $\begin{array}{c}\text { Influenza } \\
\text { Vaccination } \\
\%(95 \% \mathrm{Cl})\end{array}$ & $\begin{array}{c}\text { Mammogram } \\
\%(95 \% \mathrm{Cl})\end{array}$ & $\begin{array}{c}\text { Dental } \\
\text { Checkup } \\
\%(95 \% \mathrm{Cl})\end{array}$ \\
\hline \multicolumn{5}{|l|}{ Race/ethnicity } \\
\hline White & $27(24-29)^{b}$ & $74(71-77)^{b}$ & 65 (62-69) & $63(59-66)^{b}$ \\
\hline Black & $49(41-56)^{b}$ & $59(53-65)^{b}$ & $68(58-77)$ & $44(38-51)^{b}$ \\
\hline Hispanic & $41(32-50)^{b}$ & $63(52-73)^{b}$ & $75(68-82)$ & $56(46-65)^{b}$ \\
\hline \multicolumn{5}{|c|}{ Educational attainment } \\
\hline > High School & $20(16-24)^{b}$ & $76(72-80)^{b}$ & $76(71-81)^{b}$ & $77(73-81)^{b}$ \\
\hline High Schoola & $27(23-30)^{b}$ & $74(68-78)^{b}$ & $62(56-68)^{\mathrm{b}}$ & $60(56-65)^{b}$ \\
\hline$<$ High School & $48(43-53)^{b}$ & $64(59-69)^{b}$ & $59(53-65)^{\mathrm{b}}$ & $35(30-40)^{b}$ \\
\hline \multicolumn{5}{|c|}{$\begin{array}{l}\text { Source: Data used are from the } 2003 \text { National Assessment of Adult Literacy, conducted by the National Center for } \\
\text { Education Statistics, Institute of Education Sciences, US Department of Education. }\end{array}$} \\
\hline \multicolumn{5}{|c|}{$\begin{array}{l}\text { a High school diploma or equivalency degree. } \\
\text { b } P<.05 \text {. }\end{array}$} \\
\hline
\end{tabular}

Hispanic older adults (143, within the below basic level). Likewise, a gradient was seen in the average health literacy scores by educational attainment, with "greater than high school" at the high end (237, within the intermediate level), followed by "high school or equivalency" (214, within the basic level), and with "less than high school attainment" (167, within the below basic level) at the low end. The significant association of race/ethnicity or educational attainment with health literacy scores was also confirmed through multiple regressions that controlled for several confounding variables - age, household income, nativity, and marriage status (Supplemental Table 1, available online at http://www.annfammed. org/cgi/content/full/7/3/204/DC1).

To determine whether the second criterion of a potential mediator was satisfied, the associations of race/ethnicity and educational attainment with each of the health outcomes were assessed after statistical adjustment. MML probit regressions were used to control for potential confounding factors and to examine the adjusted relationship of race/ethnicity and education to health status and preventive health behaviors (Table 3, model A). The likelihood of fair or poor self-rated health was greater for blacks than whites and for those with less than high school attainment than for those with more than high school attainment. This pattern of disparity was also evident in the utilization of influenza vaccination.

Black and Latina women were not less likely to utilize mammography or dental care services (in fact, Latinas were more likely than white women to report a mammogram). A disparity was observed for educational attainment, however-older adults with less than high school attainment as well as those with only a high school or equivalent degree were less likely to receive a mammogram or dental care than older adults with more than high school attainment.

To determine whether health literacy contributed to the disparities identified, we then added health literacy to the previous regression models to find out whether health literacy was significantly associated with each health outcome, while controlling for the primary independent variables, and whether the $\beta$ coefficients estimating the association of race/ethnicity or educational attainment with the health outcomes were reduced compared with the regression models without health literacy. As shown in columns with a heading of B in Table 3 , there was an independent association between increased health literacy and the likelihood that an older adult would report good or better health, or having received influenza vaccination, mammography, or dental care in the year preceding the assessment. There was also a reduction in the association of race/ethnicity (black vs white) with health status and influenza vaccination, as well as in the association between educational attainment and all of the health outcomes. These results indicated mediation effects of health literacy. The Sobel test was then carried out to check for significant mediation by health literacy of the 2 racial/ethnic and 4 education-related health disparities that met criteria for possible mediation. As shown in Supplemental Table 2 (available online at: http://www.annfammed.org/ cgi/content/full/7/3/204/DC1), all the Sobel tests for these 6 cases showed statistically significant $(P<.001)$ mediation by health literacy.

\section{DISCUSSION}

The findings from this study provide evidence that one component of health literacy, namely, health-related print literacy, significantly mediates racial/ethnic (black vs white) disparities in self-rated health status and receiving an influenza vaccination, as well as contributes to the education-related disparities in self-rated health status and utilization of influenza vaccination, mammography, and dental care services.

Our findings are consistent with those of a previous analysis of the data from assessment of general literacy 


\begin{tabular}{|c|c|c|c|c|c|c|c|c|}
\hline \multirow[b]{2}{*}{ Variable } & \multicolumn{2}{|c|}{$\begin{array}{l}\text { Self-Rated Health } \\
\text { Status } \\
\beta \text { (SE) }\end{array}$} & \multicolumn{2}{|c|}{$\begin{array}{l}\text { Influenza } \\
\text { Vaccination } \\
\beta \text { (SE) }\end{array}$} & \multicolumn{2}{|c|}{$\begin{array}{c}\text { Mammogram } \\
\beta \text { (SE) }\end{array}$} & \multicolumn{2}{|c|}{$\begin{array}{c}\text { Dental Checkup } \\
\beta \text { (SE) }\end{array}$} \\
\hline & A & B & A & B & A & B & A & B \\
\hline \multicolumn{9}{|l|}{ Race/ethnicity } \\
\hline White & Ref & Ref & Ref & Ref & Ref & Ref & Ref & Ref \\
\hline Black & $\begin{array}{l}-0.34^{\mathrm{a}} \\
(0.11)\end{array}$ & $\begin{array}{r}-0.24^{\mathrm{a}} \\
(0.04)\end{array}$ & $\begin{array}{r}-0.24^{\mathrm{a}} \\
(0.10)\end{array}$ & $\begin{array}{r}-0.18^{a} \\
(0.04)\end{array}$ & $\begin{array}{c}0.23 \\
(0.15)\end{array}$ & $\begin{array}{r}0.28^{a} \\
(0.06)\end{array}$ & $\begin{array}{c}-0.13 \\
(0.11)\end{array}$ & $\begin{array}{c}-0.04 \\
(0.04)\end{array}$ \\
\hline Latino/Hispanic & $\begin{array}{c}0.02 \\
(0.14)\end{array}$ & $\begin{array}{r}0.21^{\mathrm{a}} \\
(0.07)\end{array}$ & $\begin{array}{c}-0.04 \\
(0.16)\end{array}$ & $\begin{array}{c}0.08 \\
(0.07)\end{array}$ & $\begin{array}{r}0.57^{\mathrm{a}} \\
(0.19)\end{array}$ & $\begin{array}{r}0.70^{a} \\
(0.07)\end{array}$ & $\begin{array}{c}0.19 \\
(0.14)\end{array}$ & $\begin{array}{r}0.35^{\mathrm{a}} \\
(0.05)\end{array}$ \\
\hline Other & $\begin{array}{l}-0.11 \\
(0.30)\end{array}$ & $\begin{array}{c}-0.09 \\
(0.10)\end{array}$ & $\begin{array}{c}0.22 \\
(0.19)\end{array}$ & $\begin{array}{r}0.24^{a} \\
(0.08)\end{array}$ & $\begin{array}{c}-0.01 \\
(0.25)\end{array}$ & $\begin{array}{l}0.02 \\
(0.09)\end{array}$ & $\begin{array}{c}-0.21 \\
(0.32)\end{array}$ & $\begin{array}{c}-0.20 \\
(0.12)\end{array}$ \\
\hline \multicolumn{9}{|l|}{ Education } \\
\hline > High school & Ref & Ref & Ref & Ref & Ref & Ref & Ref & Ref \\
\hline High school or equivalency & $\begin{array}{l}-0.17 \\
(0.11)\end{array}$ & $\begin{array}{l}-0.08 \\
(0.05)\end{array}$ & $\begin{array}{l}-0.08 \\
(0.10)\end{array}$ & $\begin{array}{l}-0.03 \\
(0.04)\end{array}$ & $\begin{array}{l}-0.40^{\mathrm{a}} \\
(0.14)\end{array}$ & $\begin{array}{r}-0.36^{a} \\
(0.06)\end{array}$ & $\begin{array}{r}-0.39^{\mathrm{a}} \\
(0.10)\end{array}$ & $\begin{array}{r}-0.31^{\mathrm{a}} \\
(0.04)\end{array}$ \\
\hline$<$ High school & $\begin{array}{l}-0.56^{a} \\
(0.12)\end{array}$ & $\begin{array}{r}-0.36^{\mathrm{a}} \\
(0.05)\end{array}$ & $\begin{array}{c}-0.31^{\mathrm{a}} \\
(0.11)\end{array}$ & $\begin{array}{r}-0.18^{\mathrm{a}} \\
(0.05)\end{array}$ & $\begin{array}{l}-0.60^{\mathrm{a}} \\
(0.13)\end{array}$ & $\begin{array}{r}-0.46^{\mathrm{a}} \\
(0.06)\end{array}$ & $\begin{array}{r}-0.97^{a} \\
(0.12)\end{array}$ & $\begin{array}{r}-0.80^{\mathrm{a}} \\
(0.05)\end{array}$ \\
\hline Health literacy ${ }^{b}$ & - & $\begin{array}{c}0.23^{\mathrm{a}} \\
(0.03)\end{array}$ & - & $\begin{array}{r}0.14^{\mathrm{a}} \\
(0.02)\end{array}$ & - & $\begin{array}{c}0.17^{\mathrm{a}} \\
(0.04)\end{array}$ & - & $\begin{array}{r}0.20^{\mathrm{a}} \\
(0.03)\end{array}$ \\
\hline Age & $\begin{array}{l}-0.02^{\mathrm{a}} \\
(0.006)\end{array}$ & $\begin{array}{l}-0.01^{\mathrm{a}} \\
(0.003)\end{array}$ & $\begin{array}{l}0.03^{\mathrm{a}} \\
(0.006)\end{array}$ & $\begin{array}{l}0.03^{\mathrm{a}} \\
(0.003)\end{array}$ & $\begin{array}{l}-0.01 \\
(0.007)\end{array}$ & $\begin{array}{l}-0.006 \\
(0.003)\end{array}$ & $\begin{array}{c}0.008 \\
(0.005)\end{array}$ & $\begin{array}{l}0.02^{\mathrm{a}} \\
(0.002)\end{array}$ \\
\hline \multicolumn{9}{|l|}{ Sexc } \\
\hline Male & Ref & Ref & Ref & Ref & - & - & Ref & Ref \\
\hline Female & $\begin{array}{c}0.19^{a} \\
(0.08)\end{array}$ & $\begin{array}{r}0.15^{\mathrm{a}} \\
(0.03)\end{array}$ & $\begin{array}{c}0.04 \\
(0.08)\end{array}$ & $\begin{array}{c}0.01 \\
(0.03)\end{array}$ & - & - & $\begin{array}{l}0.12 \\
(0.08)\end{array}$ & $\begin{array}{r}0.07^{\mathrm{a}} \\
(0.03)\end{array}$ \\
\hline \multicolumn{9}{|l|}{ Income } \\
\hline$>175 \%$ of poverty level & Ref & Ref & Ref & Ref & Ref & Ref & Ref & Ref \\
\hline $100 \%-175 \%$ poverty level & $\begin{array}{l}-0.39^{\mathrm{a}} \\
(0.11)\end{array}$ & $\begin{array}{r}-0.32^{\mathrm{a}} \\
(0.04)\end{array}$ & $\begin{array}{l}-0.07 \\
(0.10)\end{array}$ & $\begin{array}{l}-0.03 \\
(0.04)\end{array}$ & $\begin{array}{c}-0.23 \\
(0.12)\end{array}$ & $\begin{array}{r}-0.18^{a} \\
(0.05)\end{array}$ & $\begin{array}{r}-0.55^{\mathrm{a}} \\
(0.10)\end{array}$ & $\begin{array}{r}-0.49^{a} \\
(0.04)\end{array}$ \\
\hline$<$ Poverty level & $\begin{array}{c}-0.62^{\mathrm{a}} \\
(0.11)\end{array}$ & $\begin{array}{c}-0.50^{\mathrm{a}} \\
(0.05)\end{array}$ & $\begin{array}{c}-0.23^{\mathrm{a}} \\
(0.10)\end{array}$ & $\begin{array}{c}-0.16^{\mathrm{a}} \\
(0.05)\end{array}$ & $\begin{array}{c}-0.14 \\
(0.13)\end{array}$ & $\begin{array}{c}0.04 \\
(0.05)\end{array}$ & $\begin{array}{c}-0.54^{\mathrm{a}} \\
(0.13)\end{array}$ & $\begin{array}{r}-0.43^{\mathrm{a}} \\
(0.06)\end{array}$ \\
\hline \multicolumn{9}{|l|}{ Nativity } \\
\hline US born & Ref & Ref & Ref & Ref & Ref & Ref & Ref & Ref \\
\hline Foreign born & $\begin{array}{c}-0.03 \\
(0.17)\end{array}$ & $\begin{array}{c}0.10 \\
(0.07)\end{array}$ & $\begin{array}{c}-0.24 \\
(0.13)\end{array}$ & $\begin{array}{r}-0.16^{\mathrm{a}} \\
(0.05)\end{array}$ & $\begin{array}{c}-0.12 \\
(0.22)\end{array}$ & $\begin{array}{c}0.04 \\
(0.10)\end{array}$ & $\begin{array}{c}0.18 \\
(0.15)\end{array}$ & $\begin{array}{c}0.30^{\mathrm{a}} \\
(0.06)\end{array}$ \\
\hline Constant & $\begin{array}{c}2.34^{a} \\
(0.50)\end{array}$ & $\begin{array}{r}1.77^{\mathrm{a}} \\
(0.22)\end{array}$ & $\begin{array}{c}-1.13^{\mathrm{a}} \\
(0.45)\end{array}$ & $\begin{array}{c}-1.52^{\mathrm{a}} \\
(0.19)\end{array}$ & $\begin{array}{r}1.77^{\mathrm{a}} \\
(0.52)\end{array}$ & $\begin{array}{r}1.32^{\mathrm{a}} \\
(0.25)\end{array}$ & $\begin{array}{c}0.22 \\
(0.35)\end{array}$ & $\begin{array}{r}-0.33^{\mathrm{a}} \\
(0.16)\end{array}$ \\
\hline \multicolumn{9}{|c|}{ MML = marginal maximum likelihood. } \\
\hline \multicolumn{9}{|c|}{$\begin{array}{l}\text { Note: Standard errors are in parentheses. Three decimal places were kept when reporting standard error estimates of age. The small estimates were due to a much } \\
\text { larger unit of age compared with other independent variables. Model A has self-rated health status or utilization of each of the preventive health services as the } \\
\text { dependent variable, race/ethnicity and educational attainment as the independent variable, and } 4 \text { demographic variables as covariates. Model B adds health literacy as } \\
\text { an independent variable. }\end{array}$} \\
\hline \multicolumn{9}{|c|}{$\begin{array}{l}\text { Source: Data used are from the } 2003 \text { National Assessment of Adult Literacy, conducted by the National Center for Education Statistics, Institute of Education Sciences, } \\
\text { uS Department of Education. }\end{array}$} \\
\hline \multicolumn{9}{|c|}{$\begin{array}{l}\text { a Statistically significant regression coefficients in each model at the } \alpha \text { level of } .05 \text {. } \\
\text { b In the MML probit model, health literacy was measured on the item response theory (IRT) } \theta \text { scale, typically ranging from }-3 \text { to } 3 \text {. } \\
\text { ' Sex is not included in the probit model for mammogram. }\end{array}$} \\
\hline
\end{tabular}

in a nationally representative sample of all US adults, which found that the importance of race (black vs white) and education in explaining disparities in workimpairing conditions and long-term illnesses declined when general literacy was considered. ${ }^{35}$ Health literacy is a distinct contextual literacy domain effected by general literacy skill; it also brings together a unique range of skills needed for successful functioning in the health care setting. ${ }^{21,22}$ Further research is needed to determine to what extent a measure of health-related print literacy, such as the NAAL health literacy assessment, identifies skills that are truly distinct from general literacy. ${ }^{36}$ Another study found that among older adults enrolled in a single regional insurance plan, low health literacy, estimated by a widely used brief screening instrument measuring health-related reading skills, mediated disparities in health status and receipt of influenza vaccination that were associated with race/ethnicity and 
education. ${ }^{16}$ The current study not only confirms these results but extends them to additional preventive health measures and to a representative sample of the US elderly population. Importantly, our study used a direct measure of health-related print literacy skills, rather than one of the limited brief screening instruments that have been used for studies of health literacy. ${ }^{17,19}$

Our finding that health literacy mediates some disparities in preventive health care utilization adds important information to the growing understanding of the role of health literacy in the health of older adults. Racial/ethnic disparities in health care utilization often overlap with those associated with educational attainment but are generally independent. ${ }^{15,37}$ The finding that health literacy was associated with disparities between black and white older adults, but not between Hispanics and whites, is consistent with findings of previous studies. ${ }^{16,35}$ Our observation that health literacy mediated a wider range of educationrelated disparities than racial/ethnic disparities may be related to a closer link between education and literacy than race and literacy. This difference also suggests that health literacy interventions may be more useful for the reduction of some disparities than for others (ie, racial/ethnic disparities in receipt of influenza vaccination compared with dental care).

An important limitation of the current study (and all assessments of health literacy) is that the NAAL health literacy measure does not measure all the proposed domains of the health literacy construct. Healthrelated oral literacy (using spoken language for health communication) has been proposed as another major component of health literacy (although we are not aware of any studies that have assessed this skill). ${ }^{21,22}$ Oral communication is clearly important for interaction with the health care delivery system, but it is not entirely independent of print literacy. There are obvious differences between health-related written and oral texts. For example, in written text more information is lexical and integrated, whereas in oral language information tends to be fragmented, which makes comprehension more challenging. On the other hand, the oral mode uses colloquial language, prosody, and gestures-all of which facilitate comprehension. Further studies are needed to determine whether the ability to communicate orally with health care clinicians has the same association with health outcomes and health disparities as the ability to comprehend written healthrelated materials. Our study also does not directly assess the mechanisms by which low health literacy might result in disparities in health status and preventive health care utilization. There is a wide range of potential mechanisms that might vary based on the particular health outcome and that are critical because of their implications for interventions. Because current poor health status reflects chronic disease, its relationship with health literacy is presumed to be the result of negative effects of low health literacy throughout life. The consistent finding that literacy and health literacy contribute to the disparity between black and white adults in health status suggests that a life course perspective is warranted for future studies of the role of health literacy in the development and management of chronic conditions. Research in disparities of use of preventive care services should also consider the psychosocial aspects of low health literacy in adults. ${ }^{37-39}$

Our findings provide evidence that health-related print literacy is a mediator of (1) the race/ethnicityassociated disparity in self-rated health status and receipt of influenza vaccination, and of (2) the education-related disparity in these outcomes, as well as the receipt of mammography and dental care services. Based on these results, further investigations should be undertaken to determine whether reducing the obstacles to the health care associated with low health literacy results in reduced disparities in these health outcomes. Few intervention studies have addressed health literacy issues specifically to guide recommendations. ${ }^{24}$ Randomized trials have shown benefits of programs designed to address obstacles faced by patients in care for chronic illness. ${ }^{25}$ Efforts to reduce literacy-related obstacles to health care might address the skills and demands of health literacy by improving the health-related print literacy of older adults and reduce the reading level required by print materials targeting older adults. ${ }^{22}$

To read or post commentaries in response to this article, see it online at http://www.annfammed.org/cgi/content/full/7/3/204.

Key words: Aged; preventive health services; educational status; vaccination; oral health

Submitted March 22, 2008; submitted, revised, August 3, 2008; accepted September 15, 2008.

Funding support: Dr Bennett is supported by a career development grant from the National Institute of Child Health and Human Development (1K23HD048915-01A2).

\section{References}

1. Kutner M, Greenberg E, Baer J. Adult Literacy in America: A First Look at the Findings of the National Adult Literacy Survey. Washington, DC: National Center for Educational Statistics; 2005. Report No. NCES 2006470.

2. White S. Assessing the Nation's Health Literacy: Key Concepts and Findings of the National Assessment of Adult Literacy (NAAL). Chicago, IL: American Medical Association Foundation; 2008.

3. Gornick ME. A decade of research on disparities in Medicare utilization: lessons for the health and health care of vulnerable men. Am J Public Health. 2003;93(5):753-759. 
4. Joyce GF, Keeler EB, Shang B, Goldman DP. The lifetime burden of chronic disease among the elderly. Health Aff (Millwood). 2005;24(Suppl 2):W5R18-29.

5. Proceedings of the 2005 White House Conference on Aging Mini-Conference on Health Literacy and Health Disparities. Chicago, IL: American Medical Association; 2005.

6. O'Malley AS, Forrest CB. Immunization disparities in older Americans: determinants and future research needs. Am J Prev Med. 2006;31(2):150-158.

7. Miller RG, Ashar BH, Cohen J, et al. Disparities in osteoporosis screening between at-risk African-American and white women. J Gen Intern Med. 2005;20(9):847-851.

8. Chen JY, Diamant A, Pourat N, Kagawa-Singer M. Racial/ethnic disparities in the use of preventive services among the elderly. Am J Prev Med. 2005;29(5):388-395.

9. Jerant AF, Franks P, Jackson JE, Doescher MP. Age-related disparities in cancer screening: analysis of 2001 Behavioral Risk Factor Surveillance System data. Ann Fam Med. 2004;2(5):481-487.

10. Singleton JA, Santibanez TA, Wortley PM. Influenza and pneumococcal vaccination of adults aged $>$ or $=65$ : racial/ethnic differences. Am J Prev Med. 2005;29(5):412-420.

11. Meissner HI, Breen N, Klabunde CN, Vernon SW. Patterns of colorectal cancer screening uptake among men and women in the United States. Cancer Epidemiol Biomarkers Prev. 2006;15(2): 389-394

12. Link MW, Ahluwalia IB, Euler GL, Bridges CB, Chu SY, Wortley PM. Racial and ethnic disparities in influenza vaccination coverage among adults during the 2004-2005 season. Am J Epidemiol. 2006;163(6):571-578

13. Berkman ND, DeWalt DA, Pignone MP, et al. Literacy and Health Outcomes. Rockville, MD: Agency for Healthcare Research and Quality; 2004. AHRQ Publication No. 04-E007-2. Evidence Report/Technology Assessment No. 87

14. United States Department of Health and Human Services. Healthy People 2010. Washington, DC: US Department of Health and Human Services; 2000.

15. Baker DW, Wolf MS, Feinglass J, Thompson JA, Gazmararian JA, Huang J. Health literacy and mortality among elderly persons. Arch Intern Med. 2007;167(14):1503-1509.

16. Howard DH, Sentell T, Gazmararian JA. Impact of health literacy on socioeconomic and racial differences in health in an elderly population. J Gen Intern Med. 2006;21(8):857-861.

17. Davis TC, Long SW, Jackson RH, et al. Rapid estimate of adult literacy in medicine: a shortened screening instrument. Fam Med. 1993;25(6):391-395.

18. Parker RM, Baker DW, Williams MV, Nurss JR. The test of functiona health literacy in adults: a new instrument for measuring patients' literacy skills. J Gen Intern Med. 1995;10(10):537-541.

19. Nurss J, Parker RM, Williams MV, Baker DW. Directions for Administration and Scoring and Technical Data, Short Test of Functional Health Literacy in Adults (STOFHLA-English and STOFHLA-Spanish). Center for the Study of Adult Literacy; 1998

20. Baker DW, Gazmararian JA, Williams MV, et al. Functional health literacy and the risk of hospital admission among Medicare managed care enrollees. Am J Public Health. 2002;92(8):1278-1283.
21. Baker DW. The meaning and the measure of health literacy. J Gen Intern Med. 2006;21(8):878-883.

22. Nielson-Bohlman L, Panzer A, Kindig D, eds. Health Literacy: A Prescription to End Confusion. Washington, DC: Institute of Medicine; 2004.

23. Ad Hoc Committee on Health Literacy for the Council on Scientific Affairs AMA. Health literacy: report of the Council on Scientific Affairs. JAMA. 1999;281(6):552-557.

24. Pignone M, DeWalt DA, Sheridan S, Berkman N, Lohr KN. Interventions to improve health outcomes for patients with low literacy. A systematic review. J Gen Intern Med. 2005;20(2):185-192.

25. DeWalt DA, Malone RM, Bryant ME, et al. A heart failure self-management program for patients of all literacy levels: a randomized, controlled trial [ISRCTN11535170]. BMC Health Serv Res. 2006;6:30.

26. Ware JE Jr, Sherbourne CD. The MOS 36-item short-form health survey (SF-36). I. Conceptual framework and item selection. Med Care. 1992;30(6):473-483.

27. White S, Dillow S. Key Concepts and Features of the 2003 National Assessment of Adult Literacy Washington, DC: US Department of Education, Institute of Education Sciences; 2005. NCES Report No. 2006-471.

28. Cohen J. User Guide: AM Statistical Software. http://am.air.org. Accessed Jul 19, 2006.

29. Bock RD. M A. Marginal Maximum Likelihood estimation of item parameters: application of an EM algorithm. Psychometrika. 1981;46:443-459.

30. Cohen JD, Jiang T. Comparison of partially measured latent traits across nominal subgroups. J Am Stat Assoc. 1999;94(448):1035-1044.

31. Baron RM, Kenny DA. The moderator-mediator variable distinction in social psychological research: conceptual, strategic, and statistical considerations. J Pers Soc Psychol. 1986;51(6):1173-1182.

32. Sobel M. Asymptotic confidence intervals for indirect effects in structural equation models. In: Leinhart S, ed. Sociological Methodology. San Francisco, CA: Jossey-Bass; 1982:290-312.

33. Aroian L. The probability function of the product of two normally distributed variables. Ann Math Stat. 1944;18(2):265-271.

34. MacKinnon DP, Krull JL, Lockwood CM. Equivalence of the mediation, confounding and suppression effect. Prev Sci. 2000;1(4):173-181.

35. Sentell TL, Halpin HA. Importance of adult literacy in understanding health disparities. J Gen Intern Med. 2006;21(8):862-866.

36. Rudd R, Kirsch I, Yamamoto K. Literacy and Health in America. Princeton, NJ: Policy Information Center, Educational Testing Service; 2004.

37. Geiger H. Racial and ethnic disparities in diagnosis and treatment: a review of the evidence and a consideration of the causes. In: Smedley BD, Stith AY, Nelson AR, eds. Unequal Treatment: Confronting Racial and Ethnic Disparities in Health Care. Washington, DC: The National Academies Press; 2003.

38. Baker DW, Parker R, Williams M, et al. The health care experience of patients with low literacy. Arch Fam Med. 1996;5(6):329-334.

39. Bennett I, Switzer J, Aguirre AC, Evans K, Barg F. "Breaking it down:" patient-provider communication and prenatal care utilization among African American women with low and higher literacy. Ann Fam Med. 2006;4(4):334-340. 